\title{
Sociodemographic factors as predictors of sexual behavior of secondary school students in Lagos State, Nigeria
}

Olusoji T. Ayoade, Femi J. Blavo, Adekunbi A. Farotimi ${ }^{1}$, Chinomso U. Nwozichi ${ }^{1}$

Department of Physical and Health Education, Adeniran Ogunsanya College of Education, Lagos, ${ }^{1}$ Department of Adult Health, School of Nursing, Babcock University, llishan-Remo, Ogun State, Nigeria

Address for the Correspondence: Mr. Chinomso U. Nwozichi, Department of Adult Health, School of Nursing, Babcock University, Ilishan-Remo, Ogun State, Nigeria. E-mail: nwozichichinomso@gmail.

com

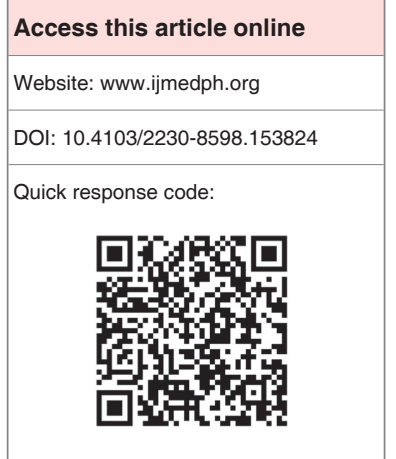

Background: Secondary school students are exposed to risky sexual behaviors that put them at certain risk of negative consequences. The aim of this study was to investigate the sociodemographic factors as predictors of sexual behavior of secondary school students in Lagos State, Nigeria. Materials and Methods: A survey design was used for the study. The data were collected using self-developed structured questionnaire called youth sexual behavior questionnaire, the co-variates collected in the questionnaire were: Gender, age and sociological factors. The instrument had test-retest reliability co-efficient of 0.78 while purposive sampling technique was used to select the schools and respondents. Totally, 2720 students were randomly selected for the study and inferential statistics of multiple regression, mean, $t$-test and ANOVA were used to analyze the data. Results: Results indicated that all the three co-variates used in the study were significant. Which shows a significant value for gender, age and sociological factors respectively $(t=6.753, P<0.05), F_{(3,2350)}$ (79.930, $P<0.05)$ and $F_{(4,2394)}(260.020 P<0.05)$. Majority of the students were of the opinion that they engaged in premarital sexual activities despite its attendant consequences. Conclusion: Gender, age and sociological factors could influence the sexual behavior of secondary school students in Lagos State significantly; it was also observed that most of these factors negatively influence youth's sexual activities.

Key words: Secondary school students, sexual behavior, sociodemographic

\section{INTRODUCTION}

The populations of the adolescents and the young adults have increased significantly over the years. There has been an observation that the population of young people between the ages of 10 and 24 is becoming larger than it used to be in history. ${ }^{[1]}$ This group of people account for $>20 \%$ of the subSaharan African population. ${ }^{[2]}$ These adolescents and young people are considered as assets to the community and have the potentials to contribute positively to global development. ${ }^{[3]}$

Sexual interests among adolescents, as among adults, can vary greatly. Sexual activity in general is associated with various risks including unwanted pregnancy and sexually transmitted diseases including HIV/AIDS. The risks are elevated for young adolescents because they are sexually active. Adolescents and young adults have been found to develop varying degrees of increased in the opposite sex, and they are usually interested in both physical and sexual attractiveness. These tendencies expose them to certain risks. In addition, adolescents are more likely to make decisions without making a thorough consideration of the consequences. ${ }^{[4]}$

According to Butler, gender has increasingly been seen not simply as lived, but as "performed" through the constant iteration and reenactment of what are regarded as the essential characteristics of both sex (male and female) and gender. ${ }^{[5]}$ In such theorizations, we seem to move ever further from any preexisting essence of femininity or masculinity. ${ }^{[6]}$ Sexuality may always have been an arena of moral and cultural conflict, but in contemporary societies sexuality is becoming an increasingly central and explicitly debated issue in mainstream cultural conflicts and political debates over values and citizenship. The fear aroused by the HIV/AIDS epidemic was more than simply concern about a new and possibly incurable disease; it also underlined our uncertainty about contemporary moral 
stances. Abortion, sex education, same-sex marriage, and the family are keystone issues on which views seem irreconcilable because they speak of the sort of society we are, and want.

Sexuality is a psychosocial phenomenon in adolescence. The increased production of androgen the hormone that is mainly responsible for an increase in sexual drive makes the adolescents experience a new sexual and drive urge, making them increasingly aware of their own sexuality, this new awareness greatly influences the adolescents' emotion and self-concept. ${ }^{[7]}$

The impact of certain sociodemographic factors on sexual behaviors of adolescents have been investigated by various researchers and they found out that educational level of household and the influence of urban and rural settlement have roles to play in the sexual behaviors among adolescents. ${ }^{[8,9]}$ Studies by other researchers have found religion to have an impact on sexual behavior among adolescents in Africa. ${ }^{[10-12]}$ Other sociodemographic factors that may have a direct influence on sexual behaviors are young age, ${ }^{[12-14]}$ female sex, ${ }^{[12,14]}$ and urban residence. ${ }^{[15,16]}$

Sexual development and awareness implies that adolescents have to develop coping skills that would help them in the proper management and expression of their natural sexual feelings, ${ }^{[17]}$ this is necessary particularly within the social and cultural context in which adolescents find themselves. ${ }^{[18]}$ Cognitive changes in the adolescents play a significant part in the nature of sexuality.

Several risky sexual behaviors among students and adolescents have created a dilapidated environment that tends to eliminate a supposedly useful population. Painstaking studies have been conducted to evaluate the factors which are specifically responsible for this trend, ${ }^{[19,20]}$ and it was observed that the current trend of sexual behaviors among young people could be linked to various customs, rapid urbanization, family background, peer pressure, economic situation, gender and educational background of parents. ${ }^{[19,20]}$

Although, HIV/AIDS and other related sexually transmitted diseases affect all age groups of the population, the most vulnerable groups are the young people, most especially females. Research has found that the impact is more among young females than young males. ${ }^{[21]} \mathrm{In}$ a study conducted in Cameroon, findings showed that young people were mostly engaged in risky sexual behaviors. ${ }^{[2]}$ Despite relatively high knowledge from different sources toward bringing about positive sexual changes, unprotected sexual practices remains a challenge among adolescents.

Having multiple sexual partners is a common sexual behavior among young people. Finding of a study conducted in $\operatorname{Uganda}^{[23,24]}$ and the one conducted in Ibadan, Nigeria ${ }^{[25]}$ proved that gender and religion were major predictors of multiple sexual partners among youths.

This present study, basically investigated the sociodemographic factors as predictors of sexual behavior of secondary school students in Lagos State, Nigeria.

\section{Research hypotheses}

The following hypotheses were tested:

1. Age will not have a significant effect on the sexual behavior of secondary school students in Lagos State.

2. Gender will not have a significant effect on the sexual behavior of secondary school students in Lagos State.

3. Sociological factors of peer group, mass media, family and teachers will not have significant prediction on sexual behavior of secondary school students in Lagos State.

\section{MATERIALS AND METHODS}

\section{Sample and instrumentation}

The descriptive survey design was used for the study; the population comprised 2720 students as respondents, randomly selected from 17 secondary schools comprising of both junior and senior schools in Lagos State. The instrument used for the study was a selfdeveloped structured questionnaire, validated by experts in the field of health promotion and education evaluation. The instrument was pretested using 20 students from another school in Lagos that did not form part of the study. The pretest result that was analyzed using Pearson product moment correlation coefficient (PPMC) showed no ambiguities in the instrument. The response format for the questionnaire was strongly agreed (SA), Agreed (A) Disagreed (D) and Strongly Disagreed (SD). Items generated on the questionnaire relating to sexual behavior include discussion about sex, engagement in sexual practices, and sexual-media relationship/information among others. The response format on the questionnaire was coded to allow for easy analysis. The following code was allocated to the responses.

- $\quad$ Strongly agreed (SA) (4)

- $\quad$ Agreed (A) (3)

- $\quad$ Disagreed (D) (2)

- $\quad$ Strongly disagreed (SD) (1).

The sociological factors used in this study comprised peer pressure, mass-media, family and teachers influence. The data was collected using a questionnaire titled youth social factor behavior questionnaire. Four items were generated on the variables each, and they were validated by experts and its reliability determined with the use of PPMC that obtained a final result of 0.78 .

\section{Data collection and analysis}

The instrument was administered to the respondents by the researchers and the research assistants. 2720 questionnaires were administered in total; the questionnaires were administered using purposive sampling technique, because the main objective of the researchers was to get directly to the set of student population whom are vulnerable to negative sexual behavior. Ethical permission was also granted by the ethical committee of each of the schools involved in the study. The questionnaire had a brief introduction to it which included the consent of the respondents, to allow them respond and understand the 
essence of the study after which all participants gave their voluntary consent.

The completed questionnaires were collated, coded and analyzed using both descriptive and inferential statistics. Descriptive statistics of frequency counts, percentages, means, standard deviation were used to analyze the Section A part of the questionnaires which dealt with the bio-data of the respondents while inferential statistics of PPMC, multiple regression, $t$-test and ANOVA were used to test the hypotheses. All the hypotheses were tested at 0.05 level of significance.

\section{RESULTS}

Table 1 above shows the names of the schools of the respondents. A breakdown of the figures as shown below indicates that 171 (6.3\%) of the respondents were selected from the Apostolic Church Grammar School, 164 (6.0\%) respondents were selected each from Dolphin high School, Epe Grammar School respectively. More so, $163(6.0 \%)$ respondents were selected each from Government College, Kosofe College and Badagry Grammar school respectively. Similarly, 166 (6.1\%) respondents were selected from Clegg High School, 154 (5.6\%) respondents from Festac Girls Secondary School and 159 (5.8\%) from Otto-Awori Secondary School. In the same vein, 165 (6.1\%) respondents were selected each from Igando Community High School and Eric Moore High School respectively while 162 (6.0\%) respondents were selected each from Iba Housing Estate Secondary School and Epe Girls High respectively. Equally, $167(6.2 \%)$ respondents were selected from Isale Eko Grammar School, 169 (6.2\%) from Gbaja boys High School, 157 (5.8\%) from Abesan High School and lastly, 106 (3.9\%) respondents were selected from Amuwo-Odofin Secondary School.

Table 2 above shows the frequency distribution of respondents by nature of school. The result shows that $169(6.2 \%)$ respondents were selected from Boys school only, 471 (17.3\%) respondents from girls' school while $2080(76.5 \%)$ respondents were selected from mixed schools.

Table 3 above shows the frequency distribution of the respondents by class. The result shows that $355(13.1 \%)$ respondents were selected from Basic 7 classes, 741 (27.2\%) respondents from Basic 8 classes, $788(28.9 \%)$ respondents from SSS1 and 836 (30.7\%) respondents from SSS2 classes respectively.

\section{Hypothesis 1}

Age will not have a significant effect on the sexual behavior of secondary school students in Lagos State.

Table 4 shows that $F_{(3,2350)}$ observed indicating the effect of age on sexual behavior is $72.9 P<0.05$. Since the $P<0.05$, the null hypothesis is therefore rejected. The results connotes that there is a significant effect of age on the sexual behavior of secondary school students in Lagos State.

\section{Hypothesis 2}

Gender will not have a significant effect on the sexual behavior of secondary school students in Lagos State.

Table 5 shows that tobserved indicating the difference between male and female behavior is $6.8, P<0.05$. Since the $P<0.05$, the null hypothesis is rejected. The result implies that there is a significant effect of gender on the sexual behavior of secondary school students in Lagos State. The results equally showed that the mean difference is higher among the male (11.2) students than that of the female students (11.2).

\section{Hypothesis 3}

Sociological factors of peer group, mass media, family and teachers influence will not have significant prediction on sexual behavior of secondary school students in Lagos State.

\begin{tabular}{|c|c|c|c|}
\hline Schools & Zonal offices & Frequency & Percentage \\
\hline The Apostolic Church Grammar School & Kosofe & 171 & 6.3 \\
\hline Dolphin High School Adeniji Adele & Lagos & 164 & 6.0 \\
\hline Government College Ajara & Badagry & 163 & 6.0 \\
\hline Clegg High School Surulere & Surulere & 166 & 6.1 \\
\hline FESTAC Girls Secondary School & Amuwo Odofin & 154 & 5.6 \\
\hline Otto-Awori Secondary School, Otto & Otto/ljanikin & 159 & 5.8 \\
\hline Igando Community High School & Alimosho & 165 & 6.1 \\
\hline Epe Grammar School & Epe & 164 & 6.0 \\
\hline Iba Housing Estate Secondary School, Iba & Ojo & 162 & 6.0 \\
\hline Isale Eko Grammar School, Jankara & Lagos Island & 167 & 6.2 \\
\hline Kosofe College Mile 2, Ikorodu Road & Kosofe & 163 & 6.0 \\
\hline Eric Moore High School, Surulere & Surulere & 165 & 6.1 \\
\hline Gbaja Boys High School, Surulere & Surulere & 169 & 6.2 \\
\hline Abesan high High School, Abesan & Alimosho & 157 & 5.8 \\
\hline Epe Girls High School, Epe & Epe & 162 & 6.0 \\
\hline Badagry Grammar School, Badagry & Badagry & 163 & 6.0 \\
\hline Amuwo-Odofin Secondary School Mile 2 & Amuwo-Odofin & 106 & 3.9 \\
\hline Total & & 2720 & 100.0 \\
\hline
\end{tabular}


Table 6 shows that the multiple prediction coefficients between the sociological factors of peer group pressure, mass media, family and teachers influence on sexual behavior of secondary school students is 0.550 . Estimated $R^{2}=0.303$ while adjusted $R^{2}=0.302$. This meant that sociological factors when taken together accounts for about $30 \%$ variation in sexual behavior of secondary school students. Further analysis on prediction of sociological factors on sexual behavior using regression ANOVA produced $F_{(4.2394)} 260.020, P<0.05$. Since $P<0.05$ then the null hypotheses is rejected, this simply means that sociological factors of peer group pressure, media influence, family influence, and teachers influence predict sexual behavior significantly at 0.05 alpha level.

It was further discovered as shown in Table 7 that peer group pressure contributed most $(\beta=0.28 ; t=11.73 ; P<0.05)$ to sexual behavior of secondary school students. Next to peer group pressure is teachers influence with $(\beta=0.20 ; t=8.96 ; P<0.05)$; followed by media influence with $(\beta=0.14 ; t=6.66 ; P<0.05)$; and lastly family influence contributed the least among others with $(\beta=0.056$; $t=2.43 ; P<0.05)$. All the factors however, contributed significantly to sexual behavior of secondary school students.

\section{DISCUSSION OF FINDINGS}

The findings of the study revealed that there is a significant effect of age on the sexual behavior of secondary school students. It is apparent therefore that, the sexual behavior is higher among the students that are in the ages of 19-21 years and equally high in the age group of 16-18 years. Majority of the students that fell within these age groups are senior students who were matured for sexual activities. Their responses revealed that they have had sexual intercourse before, and colossal number of them has had sexual experience before 15 years. Some of them indicated that, they have not only experienced pregnancy, but had sex with $>1$ sexual partner. It is observed that the sexual behavior is a bit lower in the age group of 22 years and above. The reason may be attributed to high level of their maturity that had led them to being able to take positive decisions and exercise control on sexual matters while the sexual behaviors was least noticed in the age range of 13-15 years. The reason at that time could be as a result of the age bracket, which comprised the junior students who were not fully matured for sexual activities. Many of these students were yet to develop traits of secondary sexual characteristics that are physical evidences for sexual maturity. There is a similarity between this findings and findings of other studies that supported that age has a tremendous role to play in sexual behaviors. ${ }^{[12,14]}$
The result in the second hypothesis revealed that there is a significant difference between the sexual behavior of male and female students. The above findings proved that the sexual behavioral difference is higher among male students than female students. The finding is in agreement

\begin{tabular}{lcc}
$\begin{array}{l}\text { Table 2: Frequency distribution of respondents } \\
\text { by nature of school }\end{array}$ & \\
\hline Nature of school & Frequency & Percentage \\
\hline Boys only & 169 & 6.2 \\
Girls only & 471 & 17.3 \\
Mixed school & 2080 & 76.5 \\
Total & 2720 & 100.0 \\
\hline
\end{tabular}

\begin{tabular}{lcc}
$\begin{array}{l}\text { Table 3: Frequency distribution of respondents } \\
\text { by class }\end{array}$ & Frequency & Percentage \\
\hline Class & 355 & 13.1 \\
\hline Basic 7 & 741 & 27.2 \\
Basic 8 & 788 & 28.9 \\
SSS 1 & 836 & 30.7 \\
SSS 2 & 2720 & 100.0 \\
Total & & \\
\hline
\end{tabular}

SSS = Senior secondary school

\begin{tabular}{|c|c|c|c|c|c|}
\hline $\begin{array}{l}\text { Sources of } \\
\text { variance }\end{array}$ & $\begin{array}{l}\text { Sum of } \\
\text { squares }\end{array}$ & df & $\begin{array}{l}\text { Mean } \\
\text { square }\end{array}$ & $F$ & $P$ \\
\hline Between groups & 1185.3 & 3 & 395.1 & 72.9 & 0.0001 \\
\hline Within groups & $12,730.9$ & 2350 & 5.4 & & \\
\hline Total & $13,916.2$ & 2353 & & & \\
\hline
\end{tabular}

$\begin{aligned} & \text { Table 5: Mean comparison of sexual behavior by } \\
& \text { gender }\end{aligned}$
\begin{tabular}{lcccccc} 
Gender & $\boldsymbol{n}$ & Mean & SD & $\boldsymbol{t}$ observed & df & $\boldsymbol{P}$ \\
\hline Male & 1097 & 11.8 & 2.6 & 6.8 & 2413 & 0.0001 \\
Female & 1318 & 11.2 & 2.3 & & & \\
\hline
\end{tabular}

SD = Standard deviation

\begin{tabular}{|c|c|c|c|c|c|}
\hline Model & $\begin{array}{c}\text { Sum of } \\
\text { squares }\end{array}$ & df & $\begin{array}{l}\text { Mean } \\
\text { square }\end{array}$ & $F$ & $P$ \\
\hline Regression & 4357.6 & 4 & 1089.4 & 260.0 & 0.0001 \\
\hline Residual & $10,030.1$ & 2394 & 4.2 & & \\
\hline Total & $14,387.7$ & 2398 & & & \\
\hline
\end{tabular}

$R=0.550, R$ adjusted $=0.303$, Adjusted $R^{2}=0.302$

\begin{tabular}{|c|c|c|c|c|c|}
\hline Model & SE & Unstandardized coefficients & Standardized coefficient & $t$ & $P$ \\
\hline 1. (Constant) & 7.29 & 0.15 & & 50.42 & 0.0001 \\
\hline Peer group pressure & 0.24 & 0.02 & 0.28 & 11.73 & 0.0001 \\
\hline Media influence & 0.10 & 0.02 & 0.14 & 6.66 & 0.0001 \\
\hline Family influence & 0.05 & 0.02 & 0.06 & 2.43 & 0.0015 \\
\hline Teacher influence & 0.15 & 0.02 & 0.20 & 8.96 & 0.0001 \\
\hline
\end{tabular}


with other studies that have found out that gender is a major influencing factor among the young people..$^{[12,14,19-21]}$ Findings of another study gave a view that both gender and religion are very important factor in sexual behaviors among young people. ${ }^{[25]}$ Results showed generally that all the four sociological factors significantly predicted sexual behavior of secondary school students. The above finding is in agreement with another study that reported that young adults in a deliberate fostering of ignorance through false teachings by peers and its practice inhibits the natural expression of sex impulse which ultimately leads to such health problems like unwanted pregnancies and early childbearing of sex-related crimes. ${ }^{[2]]}$ What peers often think have a greater influence on sexual and other risk-taking behaviors than the opinions of the parents and older adults. Research conducted revealed that, youths major source of information includes peer pressure, which was generally reported in their findings. ${ }^{[2]}$ Again youths believed it is easier and safer to discuss personal problems and sexual matters with friends than their parents.

\section{CONCLUSION}

This study was conducted to evaluate the sociodemographic factors that serve as predictors of sexual behaviors of secondary school students in Lagos state, Nigeria. Findings revealed that age, gender, sociological factors of peer group pressure, media influence, family influence, and teachers influence could predict sexual behavior significantly. Since sexuality is part of human life, it is therefore recommended that sexual risk behaviors and related health problems among youth should be reduced. In addition, schools and other youth-serving organizations can help young people adopt lifelong attitudes and behaviors that support their health and well-being, which is capable of reducing their risk for sexually transmitted infections and unwanted pregnancy.

\section{ACKNOWLEDGEMENT}

We would like to express our profound gratitude to our participants and the authorities of the schools for their support and cooperation. Particularly, the advice and professional guidance of experts on adolescents' issues.

\section{REFERENCES}

1. UN Department of Economic and Social Affairs, Population Division: World Population Prospects; The 2010 Revision. New York; 2012.

2. UN. World Youth Report 2007: Young People's Transition to AdulthoodProgress and Challenges. New York; 2007.

3. Jejeebhoy SJ, Zavier AJ, Santhya KG. Meeting the commitments of the ICPD Programme of Action to young people. Reprod Health Matters 2013;21:18-30.

4. Zalelem A, Melkamu B, Muluken A. Risky sexual practices and associated factors for HIV/AIDS infection among private College students in Bahir Dar City, Northwest Ethiopia. ISRN Public Health 2013; 2013:1-9.

5. Butler J. Gender Trouble: Feminism and the Subversion of Identity. New York, London: Routledge; 1990.
6. Jeffrey W. Invented Moralities: Sexual Values in an Age of Uncertainty. Cambridge, New York: Columbia University Press, U.K.: Polity; 1995.

7. Udry JG. Hormonal and social determinants of adolescence sexual initiations. In: Bancrfot J, Reinisch JM, editors. Adolescence and Puberty. New York: Oxford University Press; 1990.

8. Wellings K, Collumbien M, Slaymaker E, Singh S, Hodges Z, Patel D, et al. Sexual behaviour in context: A global perspective. Lancet 2006;368: 1706-28.

9. Stephenson R. Community influences on young people's sexual behavior in 3 African countries. Am J Public Health 2009;99:102-9.

10. Sadgrov J. Keeping up appearance: Sex and religion among students in Uganda. J Relig Afr 2007;37:116-44.

11. Omoteso BA. Astudy on the sexual behaviours of University undergraduate students in South-Western Nigeria. Soc Sci Med 2006;12:129-33.

12. Sambisa W, Curtis SL, Stokes CS. Ethnic differences in sexual behaviour among unmarried adolescents and young adults in Zimbabwe. J Biosoc Sci 2010;42:1-25.

13. Center for Disease Control and Prevention. Sexually Transmitted Disease Surveillance, 2012. Atlanta: US Department of Health and Human Services; 2003.

14. Center for Disease Control and Prevention. Tracking the Epidemic: Trends in STDs in the United States. Atlanta: US Department of Health and Human Services; 2000.

15. Becker KM, Glass GE, Brathwaite W, Zenilman JM. Geographic epidemiology of gonorrhea in Baltimore, Maryland, using a geographic information system. Am J Epidemiol 1998;147:709-16.

16. Bernstein KT, Curriero FC, Jennings JM, Olthoff G, Erbelding EJ, Zenilman J. Defining core gonorrhea transmission utilizing spatial data. Am J Epidemiol 2004;160:51-8.

17. Akinboye JO. Guidance and Counselling Strategies for Handling Adolescents and Youth Problems. Ibadan: UPL; 1897.

18. Akinboye JO. Psychological Foundations of Education in Africa. Ibadan: Stirling Horden Publishers; 1996.

19. Akinleye IO, Onifade IO. Trends in Social Behaviour among Secondary School Adolescents in Ibadan. Ibadan: IFRA, Occasional Publication, Institute of African Studies; 1996.

20. Ugoji FN. Attitude of undergraduates towards contraceptive use. Pak J Soc Sci 2008:5:111-5.

21. Zarai K. Sexual experience and their correlates among Jimma University students, Jimma, Ethiopia. Ethiop J Health Sci 2002;5:21-9.

22. Rweng M. Sexual risky behaviours among young people in Bamenda, Cameroon. Int J Fam Plann 2000;26:118-23.

23. Agardh A, Tumwine G, Östergren PO. The impact of socio-demographic and religious factors upon sexual behavior among Ugandan university students. PLoS One 2011;6:e23670.

24. Agardh A, Odberg-Pettersson K, Ostergren PO. Experience of sexual coercion and risky sexual behavior among Ugandan university students. BMC Public Health 2011;11:527.

25. Sunmola AM. Evaluating the sexual behaviour, barriers to condom use and its actual use by university students in Nigeria. AIDS Care 2005; 17:457-65.

26. Adepoju AA, Daoudu MA. Fundamentals of Guidance and Counselling. Lagos: Gods Glory Publishing House; 2003. p. 96-100.

27. Makinwa-Adebusoye P. Assessment of Adolescents Reproductive Health in Nigeria. An Assessment Coordinated by CEDA and UNFPA; 1997.

How to cite this article: Ayoade OT, Blavo FJ, Farotimi AA, Nwozichi CU. Sociodemographic factors as predictors of sexual behavior of secondary school students in Lagos State, Nigeria. Int J Med Public Health 2015;5:152-6.

Source of Support: None. Conflict of Interest: None declared. 